\title{
Review Article \\ Neurological Effects of Honey: Current and Future Prospects
}

\author{
Mohammad Mijanur Rahman, ${ }^{1}$ Siew Hua Gan, ${ }^{2}$ and Md. Ibrahim Khalil ${ }^{1}$ \\ ${ }^{1}$ Department of Biochemistry and Molecular Biology, Jahangirnagar University, Savar, Dhaka 1342, Bangladesh \\ ${ }^{2}$ Human Genome Centre, School of Medical Sciences, Universiti Sains Malaysia, 16150 Kubang Kerian, Kelantan, Malaysia
}

Correspondence should be addressed to Md. Ibrahim Khalil; drmikhalil@yahoo.com

Received 23 January 2014; Accepted 25 March 2014; Published 27 April 2014

Academic Editor: Pasupuleti Visweswara Rao

Copyright (C) 2014 Mohammad Mijanur Rahman et al. This is an open access article distributed under the Creative Commons Attribution License, which permits unrestricted use, distribution, and reproduction in any medium, provided the original work is properly cited.

\begin{abstract}
Honey is the only insect-derived natural product with therapeutic, traditional, spiritual, nutritional, cosmetic, and industrial value. In addition to having excellent nutritional value, honey is a good source of physiologically active natural compounds, such as polyphenols. Unfortunately, there are very few current research projects investigating the nootropic and neuropharmacological effects of honey, and these are still in their early stages. Raw honey possesses nootropic effects, such as memory-enhancing effects, as well as neuropharmacological activities, such as anxiolytic, antinociceptive, anticonvulsant, and antidepressant activities. Research suggests that the polyphenol constituents of honey can quench biological reactive oxygen species and counter oxidative stress while restoring the cellular antioxidant defense system. Honey polyphenols are also directly involved in apoptotic activities while attenuating microglia-induced neuroinflammation. Honey polyphenols are useful in improving memory deficits and can act at the molecular level. Therefore, the ultimate biochemical impact of honey on specific neurodegenerative diseases, apoptosis, necrosis, neuroinflammation, synaptic plasticity, and behavior-modulating neural circuitry should be evaluated with appropriate mechanistic approaches using biochemical and molecular tools.
\end{abstract}

\section{Introduction}

Honey, a natural food product, is a sweet, viscous substance that is formed from the nectar of flowers by honeybees (Apis mellifera; Family: Apidae). The conversion of nectar to honey is an impressively complex process. Nectar is first collected from flowers and undergoes ripening by partial enzymatic digestion in the honey stomach of the honeybee. The ripened nectar is then matured by moisture evaporation through fanning by the bees, which leaves a moisture content of only approximately 13 to $18 \%$ in the honey [1]. Honey has been utilized by humans since prehistoric times, before civilization appeared approximately 5,500 years ago. Most ancient civilizations, such as the Egyptians, Greeks, Chinese, Mayans, Romans, and Babylonians, used honey both for nutritional purposes and for its medicinal properties [2]. Honey is the only insect-derived natural product, and it has therapeutic, religious, nutritional, cosmetic, industrial, and traditional value.

The global production of honey increased by $10 \%$, from $1,419,072$ to $1,555,980$ tons, between 2005 and 2010 [3].
In addition to the consumption of raw honey, the use of honey in beverages is also increasing in popularity. Although modern science has reported its medical benefits, honey has historically been utilized in various food products as a sweetening agent and in medicine as a therapeutic agent for wound healing and for the treatment of cataracts $[2,4]$. Raw honey has been used for centuries by traditional medical practitioners worldwide in numerous medical treatments, such as treatments for eye diseases in India, cough and sore throat in Bangladesh, leg ulcers in Ghana, and measles in Nigeria [5].

The traditional knowledge of honey and modern science are merged in "apitherapy," which denotes the medical use of honey and bee products. Apitherapy has become a major focus of research involving alternative medicine because a wide variety of well-known preventive or curative methods from folk medicine use honey to treat different ailments, and the therapeutic properties of honey have been increasingly documented in the modern scientific literature [6-8]. Recently, the oral ingestion of raw honey has been indicated for insomnia, anorexia, stomach and intestinal 
TABLE 1: An overview of composition of raw honey [22].

\begin{tabular}{lc}
\hline Nutrient & Value in $100 \mathrm{~g}$ \\
\hline Moisture & $17.10 \mathrm{~g}$ \\
Carbohydrate & $82.40 \mathrm{~g}$ \\
Glucose & $35.75 \mathrm{~g}$ \\
Fructose & $40.94 \mathrm{~g}$ \\
Sucrose & $0.89 \mathrm{~g}$ \\
Maltose & $1.44 \mathrm{~g}$ \\
Galactose & $3.10 \mathrm{~g}$ \\
Total dietary fiber & $0.20 \mathrm{~g}$ \\
Protein & $0.30 \mathrm{~g}$ \\
Total lipid (fat) & $0.00 \mathrm{~g}$ \\
Ash & $0.20 \mathrm{~g}$ \\
Energy & $304 \mathrm{kcal}$ \\
\hline
\end{tabular}

ulcers, constipation, osteoporosis, and laryngitis. Externally applied honey is used to treat athlete's foot, eczema, lip sores, and both sterile and infected wounds caused by accidents, surgery, bedsores, or burns. In many countries, including France and Germany, physicians recommend using honey as a first-line treatment for burns, superficial wounds, and in some cases, even deep lesions such as abscesses [9].

\section{Nutritional Facts about Honey}

To date, approximately 300 varieties of honey have been identified [5]. These varieties exist due to the variable types of nectar that are collected by the honeybees. Although there have been many nutritional studies of honey, only a few are representative. Carbohydrates are the main constituents of honey and contribute 95 to $97 \%$ of its dry weight. In addition to carbohydrates, honey contains numerous compounds, such as organic acids, proteins, amino acids, minerals, and vitamins $[10,11]$ (Table 1). Pure honeys were also reported to contain polyphenols, alkaloids, anthraquinone glycosides, cardiac glycosides, flavonoids, reducing compounds, and volatile compounds [12-14].

Monosaccharides, such as fructose and glucose, are the predominant sugars present in honey, and they are said to be responsible for most of the physical and nutritional characteristics of honey [15]. Smaller quantities of other types of sugars, such as disaccharides, trisaccharides, and oligosaccharides, are also present in honey. The disaccharides primarily include sucrose, galactose, alpha,beta-trehalose, gentiobiose, and laminaribiose, whereas the trisaccharides primarily include melezitose, maltotriose, 1-ketose, panose, isomaltose glucose, erlose, isomaltotriose, theanderose, centose, isopanose, and maltopentaose [15-17]. Approximately 5 to $10 \%$ of total carbohydrates are oligosaccharides, and approximately 25 different oligosaccharides have been identified $[18,19]$. Many of these sugars are not found in the nectar but are formed during the honey ripening and maturation phases.

Gluconic acid, which is a product of glucose oxidation by glucose oxidase, is the major organic acid that is found in honey; in addition, minor amounts of formic, acetic, citric, lactic, maleic, malic, oxalic, pyroglutamic, and succinic acids have also been detected [20]. These organic acids contribute to the acidic ( $\mathrm{pH}$ between 3.2 and 4.5 ) characteristic of honey [21]. However, honey can also behave as a buffer.

Honey also contains several physiologically important amino acids, including all nine essential amino acids and all nonessential amino acids except for glutamine and asparagine. Among the amino acids present, proline is predominant, followed by aspartate, glutamate, and some other types of amino acids [22]. However, in another study, proline was reported as the primary amino acid in honey, followed by lysine [23]. Enzymes that are either secreted from the hypopharyngeal glands of the bee or originate from the botanical nectars constitute the main protein component of honey. These enzymes include the bee hypopharyngeal glandderived diastase (an amylase that digests starch to maltose), invertases (e.g., saccharase and $\alpha$-glucosidase that catalyzes the conversion of sucrose to glucose and fructose), glucose oxidase (which produces hydrogen peroxide and gluconic acid from glucose), and plant-derived catalase (which regulates the production of hydrogen peroxide), along with acid phosphatase [24].

The vitamin content in honey is generally low and does not meet the recommended daily intake (RDI). Usually, all of the water-soluble vitamins are present in honey, with vitamin $\mathrm{C}$ being the most abundant. Approximately 31 different minerals have been detected in honey, including all of the major minerals, such as calcium, phosphorus, potassium, sulfur, sodium, chlorine, and magnesium (Table 2). Some essential trace minerals are also reported to be present in honey, such as rubidium (RB), silicon $(\mathrm{Si})$, zirconium $(\mathrm{Zr})$, vanadium $(\mathrm{V})$, lithium $(\mathrm{Li})$, and strontium $(\mathrm{Sr})$, as well as some trace elements, such as lead $(\mathrm{Pb})$, cadmium $(\mathrm{Cd})$, and arsenic (As), which could be present due to contaminants from surrounding environments [25]. Interestingly, the amounts of these minerals follow a geographical variation; the mineral compositions of honeys that are collected from similar regions are similar. However, several previous reports claimed that honey is a poor source of minerals $[8,22]$, whereas several other recent reports suggest that honey is rich in minerals $[26,27]$. Essential trace elements are important, particularly among growing children because of their rapid growth and development. Nevertheless, a comparison with the RDI clearly indicates that honey contains a substantial amount of several essential trace elements that would partially meet the RDI for children (Table 2). For adults, honey is a good source of potassium.

\section{Other Nonnutritional Components of Honey}

Previous studies have reported the presence of approximately 600 different volatile compounds in honey, and these compounds can be used to characterize its botanical source [28]. In addition, volatile compounds can also impart aromatic characteristics to honey and contribute to its potential biomedical activity [28]. The volatile composition of honey is generally low but includes hydrocarbons, aldehydes, alcohols, 
TABLE 2: A comparison of the minerals found in honey (major and essential trace minerals) with RDI as reported from several studies [25-27].

\begin{tabular}{lccccc}
\hline Major minerals & RDI & One tablespoon $(21 \mathrm{~g})$ & Essential trace minerals & RDI & One tablespoon (21 g) \\
\hline Calcium & $1000 \mathrm{mg}$ & $5.0 \mathrm{mg}[27]$ & Copper & $2 \mathrm{mg}$ & $0.4 \mathrm{mg}[27]$ \\
Chloride & $3400 \mathrm{mg}$ & $11.5 \mathrm{mg}[25]$ & Fluoride & $150 \mu \mathrm{g}$ & $280.0 \mu \mathrm{g}[25]$ \\
Magnesium & $350-400 \mathrm{mg}$ & $1.4 \mathrm{mg}[26]$ & Iron & $15-18 \mathrm{mg}$ & $4.6 \mathrm{mg}[27]$ \\
Phosphorus & $1000 \mathrm{mg}$ & $0.5 \mathrm{mg}[26]$ & Molybdenum & $75 \mu \mathrm{g}$ & $4.0 \mu \mathrm{g}[25]$ \\
Potassium & $3500 \mathrm{mg}$ & $21.0 \mathrm{mg}[27]$ & Selenium & $70 \mu \mathrm{g}$ & $104.0 \mu \mathrm{gg}[27]$ \\
Sodium & $2400 \mathrm{mg}$ & $2.5 \mathrm{mg}[26]$ & Zinc & $15 \mathrm{mg}$ & $1.3 \mathrm{mg}[27]$ \\
\hline
\end{tabular}

The values are daily reference values (DRVs) of RDI. The DRVs for major minerals are based on a caloric intake of 2,000 calories for adults and children (of four or more years of age). For trace elements, the RDIs that are given are the maximums for all sex and age groups [130, 131].

ketones, acid esters, benzene and its derivatives, furan and pyran, norisoprenoids, terpene and its derivatives, and sulfur, as well as cyclic compounds $[29,30]$.

Polyphenols and flavonoids, which act as antioxidants, are two important bioactive molecules that are present in honey. Emerging evidence from recent studies has confirmed the presence of approximately 30 different polyphenols in honey $[31,32]$. The total polyphenol content of honey varies from 50 to $850 \mathrm{mg} / \mathrm{kg}$, whereas the flavonoid content varies from $36 \mathrm{mg} / \mathrm{kg}$ to $150 \mathrm{mg} / \mathrm{kg}[12,33,34]$. The presence and concentrations of these polyphenols in honeys can vary depending upon the floral source and the geographical and climatic conditions. Some bioactive compounds, such as Galangin, kaempferol, quercetin, isorhamnetin, and luteolin, are present in all types of honey, whereas others, such as hesperetin and naringenin, are reported only in specific varieties [35]. Overall, the most commonly reported phenolic and flavonoid compounds in honey include ellagic acid, gallic acid, syringic acid, benzoic acid, cinnamic acid, ferulic acids, chlorogenic acid, caffeic acid, coumaric acid, myricetin, chrysin, hesperetin, isorhamnetin, quercetin, galangin, apigenin, catechin, kaempferol, naringenin, and luteolin $[7,31$, 32].

\section{Effects of Honey on Brain Structures and Functions}

4.1. Current Experimental Evidence of the Nootropic and Neuropharmacological Effects of Honey. Research from the past two decades has explored honey as an enigmatic gel that has gastroprotective, hepatoprotective, reproductive, hypoglycemic, antioxidant, antihypertensive, antibacterial, antifungal, anti-inflammatory, immunomodulatory, wound healing, cardio-protective and antitumor effects $[6,26,36$, 37]. Unfortunately, research on the nootropic and neuropharmacological effects of honey is scarce. Nevertheless, the belief that honey is a memory-boosting food supplement is actually ethnotraditional as well as ancient in nature. For instance, honey is reported to be an important component of Brahma rasayan, an Ayurvedic formulation that is prescribed to extend the lifespan and improve memory, intellect, concentration, and physical strength [38].

One established nootropic property about honey is that it assists the building and development of the entire central nervous system, particularly among newborn babies and preschool age children, which leads to the improvement of memory and growth, a reduction of anxiety, and the enhancement of intellectual performance later in life [26]. Additionally, the human brain is known to undergo postnatal development with the obvious maturation and reorganization of several structures, such as the hippocampus and cerebral cortex. It has been reported that this postnatal development occurs through neurogenesis, which occurs predominantly during childhood, and this development can also extend into adolescence and even through adulthood [39]. Empirical, but striking, evidence supporting this concept was provided by an experiment that was conducted on postmenopausal women; those who received honey showed improvements in their immediate memory but not in immediate memory after interference or in delayed recall [40]. In another study, the normal diet of two-month-old rats was supplemented with honey, and their brain function was assessed over a oneyear period. Honey-fed rats showed significantly less anxiety and better spatial memory throughout all stages compared with the control group of rats. More importantly, the spatial memory of honey-fed rats, as assessed by object recognition tasks, was significantly greater during later months (i.e., 9 and 12) [41].

In agreement with the previous study, both shortand long-term supplementations with honey at a dose of $250 \mathrm{mg} / \mathrm{kg}$ body weight significantly decreased the lipid peroxidation in brain tissue with a concomitant augmentation of superoxide dismutase (SOD) and glutathione reductase activity. Thus, honey consumption ameliorates the defense mechanism against oxidative stress and attenuated free radical-mediated molecular destruction [39]. Furthermore, honey decreased the number of degenerated neuronal cells in the hippocampal CA1 region, a region that is known to be highly susceptible to oxidative insult [42]. Theoretically, the cumulative macromolecular destruction by free radicals due to an imbalance between the prooxidant and antioxidant defense systems is implicated in aging [43]. Many studies have focused on the evidence of oxidative stress in neurodegenerative diseases, such as Alzheimer's disease (AD), mild cognitive impairment, Parkinson's disease (PD), amyotrophic lateral sclerosis (ALS), and Huntington's disease (HD) [44].

Emerging research has documented the neuropharmacological effect of honey as a nutraceutical. Oyekunle et al. [45] conducted the first such study, in which rats were fed with different concentrations of honey $(10,20$ and $40 \%)$ at a dose of $0.5 \mathrm{~mL} / 100 \mathrm{~g}$. Significant dose-dependent 
increases in exploratory activities in a hole board test and in locomotor, rearing and grooming activities in an open-field test were found in the honey-fed test groups rats compared with the control group rats. These findings indicate that the consumption of honey mitigates anxiety and exerts an excitatory effect on the central nervous system, especially at the highest nonsedative dose [45]. In another study, the neurological effects of honey were investigated by assessing spatial working memory in mice using (1) the Y-maze test and (2) pentobarbital-induced hypnosis and assessing, (3) its anxiolytic activities using hole-board and elevated plusmaze tests, (4) its anticonvulsant activity in an picrotoxin seizure model, (5) its antinociceptive activity in hot-plate and tail-flick tests, and (6) its antidepressant effects using the forced swimming test. The authors of that study concluded that honey is a functional food that possesses anxiolytic, antinociceptive, anticonvulsant, and antidepressant effects [46].

Indeed, the neuropharmacological impact of honey reflects the preliminary modulatory ability of the neural circuit and associated neurochemical systems that underlie the behavioral and molecular changes associated with the experimental paradigm. These insights into the neuropharmacological effects of honey highlight the neurological factors that are influenced by treatment with honey. Exploratory behaviors often involve the excitatory neural systems, such as the cholinergic and dopaminergic systems, whereas anxious behavior often involves the inhibitory neural system, specifically $\gamma$-aminobutyric acid (GABA) [47-49]. Several lines of experimental evidence support the hypothesis that the neuropharmacological effects of honey are mediated via dopaminergic and nonopioid central mechanisms, such as the voltage-gated sodium channel blocking hypothesis, the activation of the noradrenergic inhibitory system and/or serotonergic systems, and the GABAergic system $[45,50]$.

In addition to neural effects, glial cells may also respond to honey therapy because honey shows a neuroprotective effect in the cerebral focal-induced ischemia model in rats [51]. Moreover, honey attenuated ischemia-induced neuroinflammation by activating microglia, and neuroinflammatory processes in the brain are believed to play a crucial role in the development of neurodegenerative diseases as well as in neuronal injury associated with stroke $[52,53]$. Interestingly, ischemia-induced cognitive impairments that result from microglia- and/or astrocyte-mediated neuroinflammation were also significantly attenuated by honey therapy $[52,54]$.

\section{The Effects of Physiologically Active Moieties in Honey on Brain Function}

Oxidative stress is a common manifestation of all types of biochemical insults to the structural and functional integrity of neural cells, such as aging, neuroinflammation, and neurotoxins. The brain is highly susceptible to oxidative damage due to its high oxygen demand as well as to the high amount of polyunsaturated fatty acids (PUFAs) in the neuronal membranes [55]. Different phytochemical compounds have been shown to have scavenging activities and can activate key antioxidant enzymes in the brain, thus breaking the vicious cycle of oxidative stress and tissue damage $[56,57]$. Several supplementary research reports have suggested that the neuroprotective effect of the polyphenols present in honey involves several important activities within the brain. These effects include protection against oxidative challenge; the attenuation of neuroinflammation; the promotion of memory, learning, and cognitive function; and protection against neurotoxin-induced neuronal injury. We describe several important constituents in honey that may play this protective role.

Apigenin is a common flavonoid that is frequently identified in honey. In addition to its radical scavenging activity, apigenin protects neurons against oxygen-glucose deprivation/reperfusion-induced injury in cultured primary hippocampal neurons by improving sodium/potassium-ATPase $\left(\mathrm{Na}^{+} / \mathrm{K}^{+}\right.$-ATPase) activities [58]. Apigenin also inhibits the kainic acid-induced excitotoxicity of hippocampal cells in a dose-dependent manner by quenching reactive oxygen species and by inhibiting the depletion of reduced glutathione (GSH) levels [59]. Apigenin suppresses the interferon gamma (IFN- $\gamma$ )-induced expression of CD40, whereas the signaling of CD40 is critically involved in microglia-related immune responses in the brain. Rezai-Zadeh et al. suggested that apigenin may have neuroprotective and disease-modifying properties in several types of neurodegenerative disorders [60]. Moreover, apigenin stimulates the adult neurogenesis that underlies learning and memory [39].

Caffeic acid, another important antioxidant, is a type of phenolic acid that is present in honey, as well as in coffee, fruits and vegetables. An in vitro study has demonstrated the neuroprotective effects of caffeic acid on neuronal cells [61]. The neuroinflammatory suppression activity of caffeic acid can be inferred from the observation that caffeic acid reverses the aluminum-induced overexpression of 5lipoxygenase (5-LOX) in brain tissues [62]. Caffeic acid also prevents the aluminum-induced damage of the cerebrum that is associated with neuronal death in the hippocampus and with learning and memory deficits [62]. In vitro treatment with caffeic acid at several different concentrations has been reported to increase the acetylcholinesterase activity in the cerebral cortex, cerebellum, and hypothalamus. A similar scenario is also observed in the cerebellum, hippocampus, hypothalamus, and pons when caffeic acid is administered in vivo. All of these findings strongly support the proposition that caffeic acid improves memory by interfering with cholinergic signaling, in addition to its neuroprotective effects [63].

Catechin is a flavonoid that contributes to the antioxidant activities of honey. Several studies have repeatedly demonstrated the neuroprotective effects of catechin on neuronal death in a wide array of cellular and animal models of neurological diseases $[64,65]$. Although catechin possesses potent iron-chelating, radical-scavenging, and anti-inflammatory activities, current studies have indicated that the modulation of signal transduction pathways, cell survival, or death genes and mitochondrial function significantly contribute to the induction of cell viability [66]. For instance, according to Unno et al., the daily consumption of green tea, which contains high levels of catechin, can delay the memory regression 
that is associated with age-related brain atrophy and cognitive dysfunction [67]. Animal studies have indicated that the long-term administration of green tea may prevent agerelated learning and memory decline by modulating the transcription factor cAMP-response element binding protein (CREB) and by upregulating synaptic plasticity-related proteins in the hippocampus $[68,69]$. Similar memoryameliorating effects were also shown in the context of neurodegenerative diseases, such as $\mathrm{PD}, \mathrm{AD}$, and multiple sclerosis [64].

Chlorogenic acid is a derivative of caffeic acid and is another common phenolic acid that is found in honey. A dose-dependent protective effect of chlorogenic acid against apoptosis was observed in pheochromocytoma-12 (PC12) cell lines that were exposed to methyl mercury-induced apoptotic damage. The protective activity of chlorogenic acid was associated with a reduction in the generation of reactive oxygen species (ROS) and the attenuation of apoptosis by the activation of caspase-3 [70]. In a study by Kwon et al. [71], the neuroprotective effects of chlorogenic acid on scopolamineinduced learning and memory impairment were investigated using several behavioral tests, such as the Y-maze, passive avoidance, and Morris water maze tests. Chlorogenic acid was found to significantly improve memory-related performance in all of the tests. It was concluded that chlorogenic acid may exert antiamnesic activity via the inhibition of acetylcholinesterase and malondialdehyde in the hippocampus and frontal cortex because chlorogenic acid inhibited the acetylcholinesterase activity of the hippocampus and frontal cortex in both ex vivo and in vitro model systems [71]. Chlorogenic acid inhibits the synthesis and release of inflammatory mediators, such as tumor necrosis alpha and nitric oxide (NO), thus contributing to anti-inflammatory and analgesic activities against carrageenan-induced inflammation [72]. Therefore, the chlorogenic acid in honey might have the capacity to attenuate neuroinflammation.

Chrysin (5,7-dihydroxyflavone) is another important flavonoid antioxidant that is present in honey. A behavioral experimental model revealed that chrysin is an anxiolytic that acts as a central receptor for benzodiazepine in instances where anxiety was reported to hamper cognitive function and learning capacity [73]. A study conducted by $\mathrm{He}$ et al. [74] showed that the therapeutic potential of chrysin in neurodegeneration-associated dementia resulted from cerebral hypoperfusion. The effects of chrysin were further investigated in a rat model of cognitive deficits and brain damage generated by the permanent occlusion of the bilateral common carotid arteries [74]. Such surgically induced hypoperfusion leads to a significant increase in the escape latency in the Morris water maze, with biochemical features of neural damage, such as increases in glial fibrillary acidic protein expression and apoptosis. Interestingly, chronic treatment with chrysin significantly alleviated neuronal damage and spatial memory deficits, with a reduction in lipid peroxidation and glutathione peroxidase activity but a decrease in SOD activity [74], indicating the neuroprotective role of honey.

p-Coumaric acid is the most abundant of the three hydroxy derivatives of cinnamic acid. A previous study demonstrated the oxidative stress reduction capacity and antigenotoxic capacity of p-coumaric acid [75]. In doxorubicin-induced cardiotoxicity, p-coumaric acid was able to increase the levels of GSH, SOD, and catalase activities with a concomitant reduction of lipid peroxidation [76]. p-Coumaric acid exhibited neuroprotective effects against 5-S-cysteinyl-dopamine-induced neurotoxicity. The extent to which p-coumaric acid confers neuroprotection was reported to be equal to or greater than that observed for the flavonoids (+)-catechin, (-)-epicatechin, and quercetin [77].

Ellagic acid is a phenolic acid that is found not only in fruits and vegetables but also in honey. In addition to its antioxidant activity, ellagic acid exerts chemopreventive effects, as indicated by its antiproliferative activity [78]. Interestingly, the chemopreventive effects of ellagic acid are executed through the reduction of oxidative stress at the cellular level [30]; moreover, oxidative stress is involved in neurodegeneration and age-related memory deficits. Hence, the probable neuroprotective effect of ellagic acid is promising. Treatment with ellagic acid also restores the levels of lipid peroxides and NO (nitric oxide), the activities of catalase and paraoxonase, and the total antioxidant status of the brain to normal levels [79]. Other experiments also support the hypothesis that ellagic acid reduces oxidative stress in the brain, which is reflected by improvements in cognitive function. Ferulic acid, another polyphenol that is found in honey, is a phenolic acid. Ferulic acid can provide neuroprotection against cerebral ischemia/reperfusion injuryassociated apoptosis in rats. Ferulic acid treatment resulted in a decrease of the extent of apoptosis, with decreased levels of ICAM-1 mRNA and reduced numbers of microglia and macrophages. This phenomenon ultimately results in the downregulation of inflammation-induced oxidative stress and oxidative stress-related apoptosis [80]. In another study [81], the ameliorating effects of ferulic acid on apoptosis caused by cerebral ischemia or reperfusion were investigated. Ferulic acid was found to show neuroprotective effects against p38 mitogen-activated protein (MAP) kinase-mediated NOinduced apoptosis. It was also reported that ferulic acid inhibits Bax translocation, the release of cytochrome $c$, and p38 MAP kinase phosphorylation and enhances the expression of the GABAB1 receptor [81]. Ferulic acid could also alleviate learning and memory deficits through the concomitant inhibition of acetylcholinesterase activity and the augmentation of SOD activity while lowering the concentration of glutamic acid and malondialdehyde in the hippocampus of rats. These results suggested that the antioxidant activities of the honey may contribute to the improvement of the cholinergic system in the brain or to the inhibition of nerve injury by excitatory amino acids [82]. Ferulic acid may be useful for preventing trimethyltin-induced cognitive dysfunction as well as for boosting the activation of choline acetyltransferase (ChAT) in dementia [83].

Gallic Acid. Gallic acid prevents the apoptotic death of cortical neurons in vitro by inhibiting amyloid beta (25-35)-induced glutamate release and the generation of ROS [84]. Gallic acid possesses an antianxiolytic activity, which provided the primary evidence in support of 
the memory-ameliorating effect of gallic acid because anxiety is associated with memory disturbance [85]. The memory-ameliorating effects of gallic acid were further confirmed by Al Mansouri et al. [86], who revealed its neuroprotective effect on 6-hydroxydopamine-induced and cerebral oxidative stress-induced memory deficits. Gallic acid improved memory concomitant with increases in the total thiol pool and glutathione peroxide activity and decreased lipid peroxidation in the hippocampus and striatum [87]. However, we cannot claim that these biochemical findings are entirely responsible for the improvements in memory.

Kaempferol is a plant flavonoid that is also frequently found in honey. The toxicity of 1-methyl-4-phenyl-1,2,3,6tetrahydropyridine (MPTP), which is a neurotoxin, leads to behavioral deficits, a depletion of dopamine, reductions in SOD and glutathione peroxidase activities, and an elevation of lipid peroxidation in the substantia nigra. The administration of kaempferol has been reported to reverse all of these behavioral and biochemical alterations and to prevent the loss of TH-positive neurons that is induced by MPTP (1-methyl-4-phenyl-1,2,3,6-tetrahydropyridine) [88]. In another study, kaempferol demonstrated the ability to protect primary neurons from rotenone-induced apoptotic challenge. Specifically, kaempferol-ameliorated antioxidant defenses and antiapoptotic effects involve the enhancement of mitochondrial turnover, which is mediated by autophagy [89]. Furthermore, kaempferol may be an optimal treatment for improving cognitive function due to its positive effects on depression, mood, and cognitive functions [90].

Luteolin is a flavonoid from the flavone class that has been reported to be found in honey. As is the case for most flavonoids, luteolin has antioxidant, anti-inflammatory, and antitumor properties [91]. Luteolin also has neuroprotective effects against microglia-induced neuronal cell death. The consumption of luteolin has been found to improve the spatial working memory of aged rats by mitigating microglia-associated inflammation in the hippocampus [92]. The impairment of learning acquisition induced by cholinergic neurotoxins and muscarinic and nicotinic receptor antagonists were reported to be attenuated by luteolin. This phenomenon, however, was not observed for dopaminergic neurotoxin- and serotonergic neurotoxin-induced memory impairments, thus confirming the involvement of the central cholinergic system in the memory-restoring function of luteolin [93].

Interestingly, Tsai et al. showed that the augmenting effect of luteolin on Mn-SOD and (Cu/Zn)-SOD activity as well as on the GSH levels in the cortex and hippocampus was associated with the amelioration of amyloid beta (140)-induced oxidative stress and cognitive deficits [94]. Luteolin is believed to enhance basal synaptic transmission and facilitate the induction of long-term potentiation (LTP) by high-frequency stimulation in the dental gyrus of the hippocampus. At the molecular level, the LTP inductive effect of luteolin involves the activation of cAMP response elementbinding protein (CREB) [95].

Myricetin is another well-known flavonoid that has also been reported to be found in honey. Yasuo et al.
(1994) demonstrated that myricetin can reduce the calciuminduced increase in oxidative metabolism in rat brain neurons when administered at a concentration of $3 \mathrm{nM}$ or greater [96]. In the case of the retinoid-induced apoptosis of human neuroblastoma cells, myricetin induced neuroprotection through a protective effect against retinoid-induced oxidative stress. The neuroprotective effect of myricetin was reported to be associated with a reduction in lipid peroxidation, retinoid-induced hydrogen peroxide generation, and superoxide radical generation $\left(\mathrm{O}^{2-}\right)$, as well as an elevation of the glutathione redox status [97]. In another study, myricetin was also reported to significantly prevent D-galactose-induced cognitive impairment. The results of this study also indicated that cognitive impairment was most likely mediated by the extracellular signal-regulated kinase- (ERK-) cyclic AMP response element binding protein (CREB) signaling pathway in the hippocampus [98].

Naringenin can confer a neuroprotective effect against quinolinic acid-induced excitotoxicity mediated by elevated intracellular calcium levels, NO-mediated oxidative stress, and, consequently, cell death [99]. Amyloid beta-proteininduced free radical-mediated neurotoxicity is also attenuated by naringenin [100]. Interestingly, free radical-mediated oxidative stress is a common manifestation of both amyloid beta- and quinolinic acid-induced neurotoxicity, and it has repeatedly been implicated in neurodegeneration and cognitive deficits. In a rat model, the administration of naringenin reversed the learning, memory, and cognitive impairments caused by the intracerebroventricular administration of streptozotocin [101]. Treatment with naringenin also increases the pool of GSH and the activities of glutathione peroxidase, glutathione reductase, glutathione-Stransferase, SOD, and choline acetyltransferase in the hippocampus in a rat model of Alzheimer's disease- (AD-) type neurodegeneration with cognitive impairment (ADTNDCI), with a concomitant decrease in the loss of ChATpositive neurons and impairments in spatial learning and memory [102].

Quercetin is another flavonoid with antioxidant activity that is commonly found in honey. An in vitro study demonstrates that quercetin can inhibit oxidative insults as well as oxidative stress-dependent and independent apoptosis in a neural cell model $[103,104]$. Quercetin improves memory and hippocampal synaptic plasticity in models of memory impairment that is caused by chronic lead exposure [105]. Quercetin also exhibited neuroprotective effects against colchicine-induced cognitive impairments [106]. Another neuroprotective role confirmed for quercetin is the alleviation of neuroinflammation. According to Sharma et al., quercetin modulates an interleukin-1 beta-mediated inflammatory response in human astrocytes [107]. Quercetin also decreases the extent of ischemic injury in a lesion-repeated cerebral ischemic rat model and restores spatial memory through the suppression of hippocampal neuronal death [108, 109]. Interestingly, quercetin also showed ameliorating effects on the peripheral nervous system and the central nervous system (CNS). In another study, quercetin promoted the 
functional recovery of the spinal cord following acute injury [110].

\section{Honey as a Neuroprotective Nutraceutical}

Generally, neurodamaging insults are categorized as either endogenous or exogenous in nature. Because the neurons of the mature nervous system are postmitotic, they cannot be easily replaced by cell renewal; therefore, neuronal cell death is the most widely studied neuronal pathologies. Neurodegeneration describes the progressive loss of neural structure and function that culminates in neuronal cell death. Acute neurodegeneration is usually caused by a specific or traumatic event, such as cardiac arrest, trauma, or subarachnoid hemorrhage, whereas chronic neurodegeneration occurs within the context of a chronic disease state with a multifactorial origin, such as $\mathrm{AD}, \mathrm{PD}, \mathrm{HD}$, or amyloid lateral sclerosis [111]. The biochemical events underlying neurodegeneration include oxidative stress, mitochondrial dysfunction, excitotoxicity, neuroinflammation, misfolded protein aggregation, and a loss of functionality [112]. The ultimate fate of such a neurodamaging insult is neuronal cell death through apoptosis, necrosis, or autophagy [113]. Therefore, oxidative stress, mitochondrial dysfunction, and inflammation are prime candidates for neuroprotection [114].

Much research over the last few decades has established nutraceuticals as neuroprotective agents. In addition to the acute modulation of the antioxidant defense system, several nutraceuticals can also modulate gene expression to confer long-term protection $[115,116]$. Phytochemicals can also modify cellular behaviors by influencing receptor function as well as by modulating intracellular events, such as cellsignaling cascades $[117,118]$. Honey and its constituents can ameliorate oxidative stress and oxidative stress-related effects. The neuroprotective effects of honey are exerted at different stages of neurodegeneration and play prominent roles in early events (Figure 1).

\section{Honey as a Nootropic Nutraceutical}

Learning and memory are the most exclusive and basic functions of the brain. Synaptic plasticity is thought to be crucial for information processing in the brain and underlies the processes of learning and memory [119]. Synaptic plasticity describes the capacity of neurons to change their efficiency in neuronal transmission in response to environmental stimuli and plays an essential role in memory formation. Long-term synaptic plasticity, or long-term potentiation (LTP), is the molecular analog of long-term memory and is the cellular model that underlies the processes of learning and memory $[120,121]$. The induction, expression, and maintenance of LTP involve a series of biochemical events [122]. LTP is induced by the influx of calcium into postsynaptic neurons through a set of receptors and/or channels and is usually followed by the amplification of calcium levels due to the release of calcium from the $\mathrm{Ca}^{2+} / \mathrm{InsP}_{3}$-sensitive intracellular store $[123,124]$.

The expression of LTP involves the activation of several calcium-sensitive enzymes, which include calcium/calmodulin-regulated protein kinases (CaMKII and CaMKIV), the cAMP-dependent protein kinase A (PKA), protein kinase C (PKC), and MAPK/ERKs $[125,126]$. Signaling events downstream and enzyme activation ultimately cause the initial expression and maintenance of LTP. However, the long-term expression and maintenance of LTP requires efficient gene expression. PKA may induce changes in the expression of genes via the phosphorylation of the transcription factor CREB. Phosphorylated CREB activates the transcription of genes with an upstream cAMP response element (CRE) [127]. The activation of CREB via MAPK/ERKs is thought to be connected to PKA and PKC signaling. Furthermore, CaMKII and CaMKIV may play a role in the maintenance of LTP through its effects on CREB phosphorylation [128]. Ultimately, CREB mediates the transcription and expression of at least two sets of genes, which include genes that regulate the transcription of other genes, such as c-fos, c-jun, zif268, and Egr-3, and effector genes, such as Arc, Narp, Homer, Cox-2, and Rheb, that directly act on cells to evoke different effects, including plastic changes [129].

Current research has clarified only a portion of the involvement of honey polyphenols in memory-related signaling pathways. However, the overall body of knowledge clearly suggests the neuroprotective roles of honey and several supplementary experimental studies support its memoryimproving effects. Overall, honey or its bioactive constituents might influence multiple signaling pathways to exert its memory-improving effects (Figure 2).

\section{Concluding Remarks and Future Prospects}

The brain is the supervisory organ with critical functions, such as body homeostasis maintenance, learning, and memory. Any neurodamaging insult leads to either the death or the functional aberration of neural cells, which results in neurodegeneration and the loss of motor function and the executive functions of the brain, such as memory. There is strong scientific support for the development of nutraceutical agents as novel neuroprotective therapies, and honey is one such promising nutraceutical antioxidant. However, past research paradigms did not evaluate the neuropharmacological and nootropic effects of honey using appropriately indepth mechanistic approaches concerning biochemical and molecular interventions.

Honey has an appreciable nutritional value. Raw honey possesses anxiolytic, antinociceptive, anticonvulsant, and antidepressant effects and improves the oxidative status of the brain. Several honey supplementation studies suggest that honey polyphenols have neuroprotective and nootropic effects. Polyphenol constituents of honey quench biological reactive oxygen species that cause neurotoxicity and aging as well as the pathological deposition of misfolded proteins, such as amyloid beta. Polyphenol constituents of honey counter oxidative stress by excitotoxins, such as kainic acid and quinolinic acid, and neurotoxins, such as 5-S-cysteinyl-dopamine and 1-methyl-4-phenyl-1,2,3,6tetrahydropyridine. Honey polyphenols also counter direct 


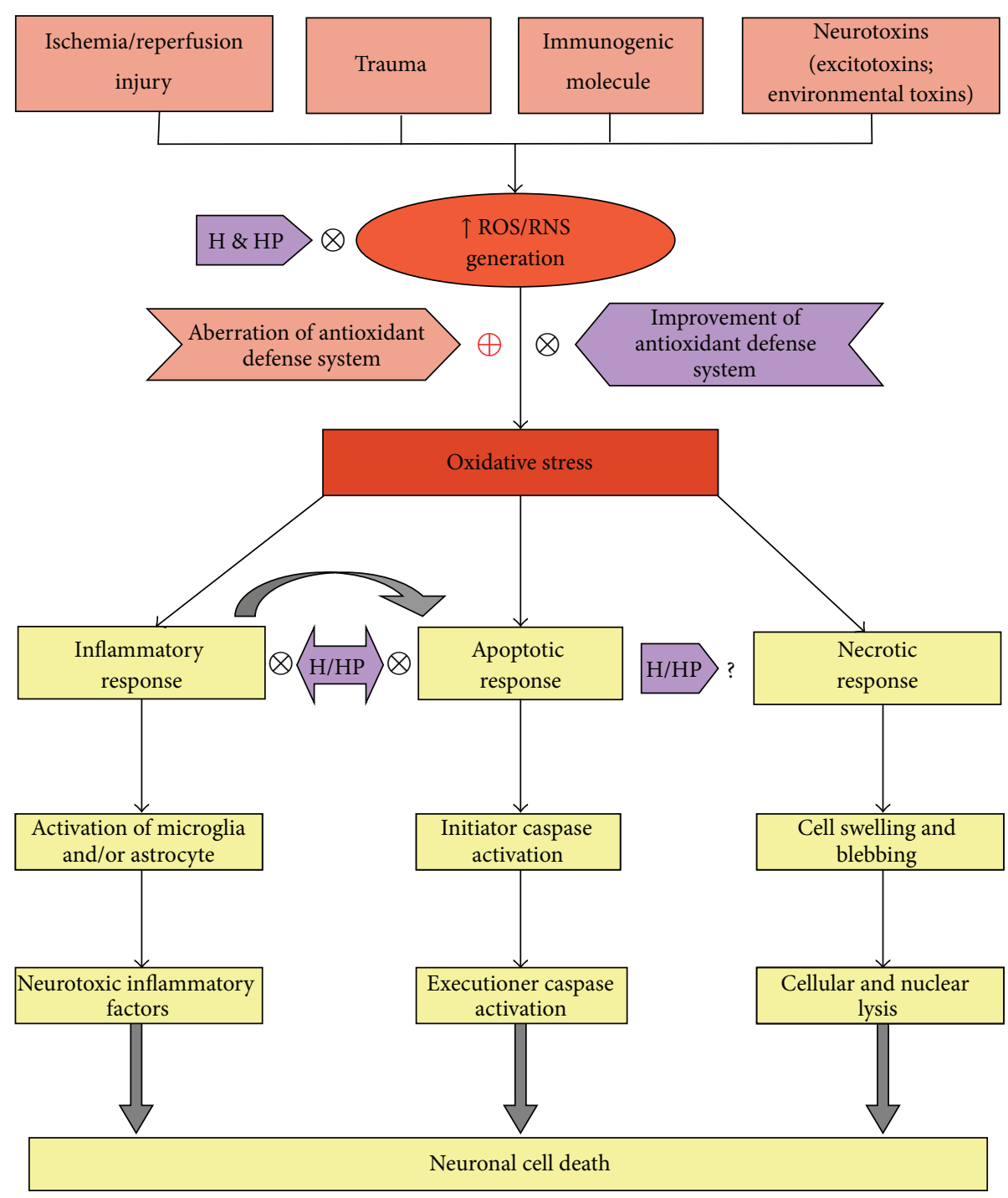

FIGURE 1: The putative neuroprotective mechanism of honey and its polyphenols. The generation of reactive oxygen species (ROS) and/or reactive nitrogen species (RNS) increases irrespective of neurodamaging insults that lead to oxidative stress. The dysfunction of the antioxidant defense system synergistically causes reactive species accumulation, leading to oxidative stress. The ultimate outcome of such oxidative stress is neuronal cell death through an inflammatory, apoptotic, or necrotic response [111-114, 116, 119]. Honey (H) and its polyphenol constituents (HP) can counter oxidative stress by limiting the generation of reactive species as well as by strengthening the cellular antioxidant defense system. Honey and several honey polyphenols (apigenin, ferulic acid, and catechin) prevent neuronal cell death by attenuating neuroinflammation and apoptosis. However, the neuroinflammatory responses overlap with apoptosis, and the role of honey in necrotic cell death remains unclear. $\mathrm{X}=$ stop or prevent and $+=$ improve or intensify.

apoptotic challenges by amyloid beta, methyl mercuryinduced, and retinoid. Raw honey and honey polyphenol attenuate the microglia-induced neuroinflammation that is induced by ischemia-reperfusion injury or immunogenic neurotoxins. Most importantly, honey polyphenols counter neuroinflammation in the hippocampus, a brain structure that is involved in spatial memory. Honey polyphenols also counter memory deficits and induce memory formation at the molecular level. Several studies suggest that the modulation of specific neural circuitry underlies the memoryameliorating and neuropharmacological effects of honey polyphenols.
Our information demands the evaluation of the benefits of raw honey and its individual constituents in specific neurodegenerative diseases, such as $\mathrm{AD}, \mathrm{PD}$, and $\mathrm{HD}$. The ultimate biochemical impact of honey on mitochondrial dysfunction, apoptosis, necrosis, excitotoxicity, and neuroinflammation should also be explored. Furthermore, exploration of the actual cell signaling cascades that are associated with synaptic plasticity may provide more specific therapeutic interventions using honey. The effect of honey on synaptic plasticity under normal and disease conditions should also be determined. The neural circuits and receptors that are involved in the neuropharmacological effects of 


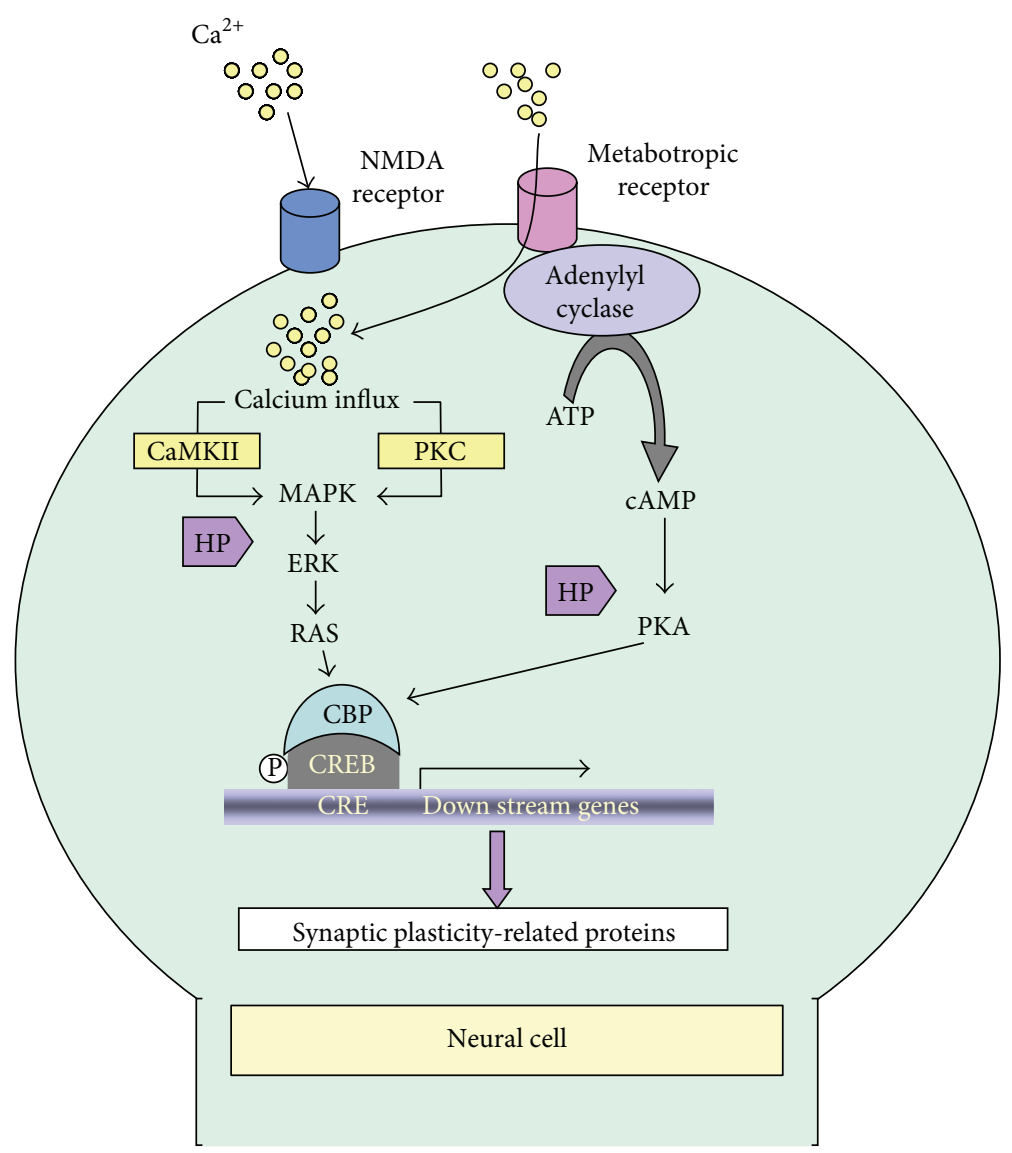

FIGURE 2: Putative nootropic mechanisms of honey and its polyphenols. Calcium influx via the N-methyl-D-aspartate receptor (NMDAR) occurs during the initial phase of NMDAR-dependent LTP. The inductive phase follows CREB phosphorylation through MAPK/ERKs signaling, which ultimately leads to the transcriptional regulation of synaptic plasticity-related proteins. Metabotropic receptors include ligand-gated ion channels that promote calcium influx (AMPA receptor) and enzyme-coupled receptors (such as cholinergic, glutamate, and dopamine receptors) that can trigger a second messenger (cAMP/cGMP) to activate downstream effector enzymes. The effector enzymes finally modulate the activation of CREB [123-128]. Honey polyphenols (HP: luteolin, myricetin, catechin) modulate synaptic plasticity through the activation of CREB by MAPK/ERKs and/or PKA-involved cellular signaling.

honey, such as anxiolytic, antinociceptive, anticonvulsant, and antidepressant activities, should be examined in further detail.

\section{Conflict of Interests}

The authors declare that there is no conflict of interests regarding the publication of this paper.

\section{References}

[1] P. B. Olaitan, O. E. Adeleke, and I. O. Ola, "Honey: a reservoir for microorganisms and an inhibitory agent for microbes," African Health Sciences, vol. 7, no. 3, pp. 159-165, 2007.

[2] J. Richard, "Honey and healing through the ages," Journal of ApiProduct and ApiMedical Science, vol. 1, no. 1, pp. 2-5, 2009.

[3] FAO, http://faostat.fao.org/.

[4] "Honeywonders. Medical uses of honey", 2013, http://www .honeywonders.com/honeyandhealth.html.
[5] N. Helmy and A. El-Soud, "Honey between traditional uses and recent medicine," Macedonian Journal of Medical Sciences, vol. 5, no. 2, pp. 205-214, 2012.

[6] C. E. Manyi-Loh, A. M. Clarke, and R. N. Ndip, "An overview of honey: therapeutic properties and contribution in nutrition and human health," African Journal of Microbiology Research, vol. 5, no. 8, pp. 844-852, 2011.

[7] O. O. Erejuwa, S. A. Sulaiman, and M. S. Ab Wahab, "Honey: a novel antioxidant," Molecules, vol. 17, no. 4, pp. 4400-4423, 2012.

[8] S. Bogdanov, T. Jurendic, R. Sieber, and P. Gallmann, "Honey for nutrition and health: a review," Journal of the American College of Nutrition, vol. 27, no. 6, pp. 677-689, 2008.

[9] American Apitherapy Society, "About Apitherapy," http:// www.apitherapy.org/about-apitherapy/products-of-the-hive2/honey.

[10] J. W. White, Composition of American Honeys, Agricultural Research Service, USDA, Washington, DC, USA, 1962.

[11] J. W. White Jr., "Detection of honey adulteration by carbohydrage analysis," Journal of the Association of Official Analytical Chemists, vol. 63, no. 1, pp. 11-18, 1980. 
[12] A. Islam, M. I. Khalil, M. N. Islam et al., "Physicochemical and antioxidant properties of Bangladeshi honeys stored for more than one year," BMC Complementary and Alternative Medicine, vol. 12, article 177, 2012.

[13] C. E. Manyi-Loh, A. M. Clarke, and R. N. Ndip, "Identification of volatile compounds in solvent extracts of honeys produced in South Africa," African Journal of Agricultural Research, vol. 6, no. 18, pp. 4327-4334, 2011.

[14] R. K. Chute, N. G. Deogade, and M. Kawale, "Antimicrobial activity of Indian honey against clinical isolates," Asiatic Journal of Biotechnology Resources, vol. 1, pp. 35-38, 2010.

[15] T. Sato and G. Miyata, "The nutraceutical benefit, part III: honey," Nutrition, vol. 16, no. 6, pp. 468-469, 2000.

[16] I. R. Siddiqui and B. Furgala, "Isolation and characterization of oligosaccharides (Disacharides) from honey," Journal of Apicultural Research, vol. 6, pp. 139-145, 1967.

[17] I. R. Siddiqui and B. Furgala, "Isolation and characterization of oligosaccharides (Trisacharides) from honey," Journal of Apicultural Research, vol. 7, pp. 51-59, 1968.

[18] L. W. Doner, "The sugars of honey-a review," Journal of the Science of Food and Agriculture, vol. 28, no. 5, pp. 443-456, 1977.

[19] I. R. Siddiqui, "The sugars of honey," Advances in Carbohydrate Chemistry and Biochemistry, vol. 25, pp. 285-309, 1971.

[20] I. Mato, J. F. Huidobro, J. Simal-Lozano, and M. T. Sancho, "Significance of nonaromatic organic acids in honey," Journal of Food Protection, vol. 66, no. 12, pp. 2371-2376, 2003.

[21] V. M. French, R. A. Cooper, and P. C. Molan, "The antibacterial activity of honey against coagulase-negative staphylococci," Journal of Antimicrobial Chemotherapy, vol. 56, no. 1, pp. 228231, 2005.

[22] USDA, "Nutrient data for honey," in USDA National Nutrient Database for Standard Reference.

[23] M. T. Iglesias, C. de Lorenzo, M. D. C. Polo, P. J. Martín-Álvarez, and E. Pueyo, "Usefulness of amino acid composition to discriminate between honeydew and floral honeys. Application to honeys from a small geographic area," Journal of Agricultural and Food Chemistry, vol. 52, no. 1, pp. 84-89, 2004.

[24] L. Vorlova and A. Pridal, "Invertase and diastase activity in honeys of Czech provenience," Acta Universitatis Agriculturae et Silviculturae Sbornik Mendelovy Zemedelske a Lesnicke Mendelianae Brunensis, no. 5, pp. 57-66, 2002.

[25] A. Abdulwahid, P. C. Joseph, and H. E. Kennedy, "Nutraceutical values of natural honey and its contribution to human health and wealth," Nutrition and Metabolism, vol. 9, article 61, 2012.

[26] M. A. Cantarelli, R. G. Pellerano, E. J. Marchevsky, and J. M. Camiña, "Quality of honey from Argentina: study of chemical composition and trace elements," Journal of the Argentine Chemical Society, vol. 96, no. 2, pp. 33-41, 2008.

[27] F. M. Adebiyi, I. Akpan, E. I. Obiajunwa, and H. B. Olaniyi, "Chemical/physical characterization of Nigerian honey," Pakistan Journal of Nutrition, vol. 3, no. 5, pp. 278-281, 2004.

[28] C. E. Manyi-Loh, R. N. Ndip, and A. M. Clarke, "Volatile compounds in honey: a review on their involvement in aroma, botanical origin determination and potential biomedical activities," International Journal of Molecular Sciences, vol. 12, no. 12, pp. 9514-9532, 2011.

[29] M. P. G. Barra, M. C. Ponce-Díaz, and C. Venegas-Gallegos, "Volatile compounds in honey produced in the central valley of Nuble province, Chile," Chilean Journal of Agricultural Research, vol. 70, no. 1, pp. 75-84, 2010.
[30] S. Nurul, S. Gan, A. Halim, N. Shah, and H. Sukari, "Analysis of volatile compounds of Malaysian Tualang (Koompassia excelsa) honey using gas chromatography mass spectrometry," African Journal of Traditional, Complementary and Alternative Medicines, vol. 10, no. 2, pp. 180-188, 2012.

[31] A. U. Carlos, H. David, and G. Carmen, "Role of honey polyphenols in health," Journal of ApiProduct and ApiMedical Science, vol. 3, no. 4, pp. 141-159, 2011.

[32] M. I. Khalil, N. Alam, M. Moniruzzaman, S. A. Sulaiman, and S. H. Gan, "Phenolic acid composition and antioxidant properties of Malaysian honeys," Journal of Food Science, vol. 76, no. 6, pp. C921-C928, 2011.

[33] H. A. Alzahrani, R. Alsabehi, L. Boukraâ, F. Abdellah, Y. Bellik, and B. A. Bakhotmah, "Antibacterial and antioxidant potency of floral honeys from different botanical and geographical origins," Molecules, vol. 17, no. 9, pp. 10540-10549, 2012.

[34] M. I. Khalil, M. Moniruzzaman, L. Boukraâ et al., "Physicochemical and antioxidant properties of Algerian honey," Molecules, vol. 17, no. 9, pp. 11199-11215, 2012.

[35] K. Petrus, H. Schwartz, and G. Sontag, "Analysis of flavonoids in honey by HPLC coupled with coulometric electrode array detection and electrospray ionization mass spectrometry," Analytical and Bioanalytical Chemistry, vol. 400, no. 8, pp. 25552563, 2011.

[36] E. J. Amy and M. E. Carlos, "Medical uses of honey," Revista Biomédica, vol. 7, pp. 43-49, 1996.

[37] M. Mandal and S. K. Jaganathan, "Antiproliferative effects of honey and of its polyphenols: a review," Journal of Biomedicine and Biotechnology, vol. 2009, Article ID 830616, 13 pages, 2009.

[38] R. N. Mishra, "Rasayan-the ayurvedic perspective," Research Journal of Pharmaceutical, Biological and Chemical Sciences, vol. 2, no. 4, pp. 269-282, 2011.

[39] O. H. Oyefuga, E. O. Ajani, B. A. Salau, F. Agboola, and O. O. Adebawo, "Honey consumption and its anti-ageing potency in white Wister albino rats," Scholarly Journal of Biological Science, vol. 1, no. 2, pp. 15-19, 2012.

[40] Z. Othman, N. Shafin, R. Zakaria, N. H. N. Hussain, and W. M. Z. W. Mohammad, "Improvement in immediate memory after 16 weeks of tualang honey (Agro Mas) supplement in healthy postmenopausal women," Menopause, vol. 18, no. 11, pp. 12191224, 2011.

[41] L. M. Chepulis, N. J. Starkey, J. R. Waas, and P. C. Molan, "The effects of long-term honey, sucrose or sugar-free diets on memory and anxiety in rats," Physiology and Behavior, vol. 97, no. 3-4, pp. 359-368, 2009.

[42] M. Cai, B. Y. Shin, D. H. Kim et al., "Neuroprotective effects of a traditional herbal prescription on transient cerebral global ischemia in gerbils," Journal of Ethnopharmacology, vol. 138, no. 3, pp. 723-730, 2011.

[43] D. Harman, "Aging: a theory based on free radical and radiation chemistry," Journal of Gerontology, vol. 11, no. 3, pp. 298-300, 1956.

[44] E. Mariani, M. C. Polidori, A. Cherubini, and P. Mecocci, "Oxidative stress in brain aging, neurodegenerative and vascular diseases: an overview," Journal of Chromatography B: Analytical Technologies in the Biomedical and Life Sciences, vol. 827, no. 1, pp. 65-75, 2005.

[45] O. A. Oyekunle, M. A. Akanmu, and T. P. Ogundeji, "Evaluation of anxiolytic and novelty induced behaviours following bee-honey consumption in rats," Journal of Neuroscience and Behavioural Health, vol. 2, no. 4, pp. 38-43, 2010. 
[46] M. A. Akanmu, T. A. Olowookere, S. A. Atunwa et al., "Neuropharmacological effects of Nigerian honey in mice," African Journal of Traditional, Complementary and Alternative Medicines, vol. 8, no. 3, pp. 230-249, 2011.

[47] J. C. Ballenger, "Current treatments of the anxiety disorders in adults," Biological Psychiatry, vol. 46, no. 11, pp. 1579-1594, 1999.

[48] M. R. Lamprea, F. P. Cardenas, R. Silveira, T. J. Walsh, and S. Morato, "Effects of septal cholinergic lesion on rat exploratory behavior in an open-field," Brazilian Journal of Medical and Biological Research, vol. 36, no. 2, pp. 233-238, 2003.

[49] J. C. Patel, E. Rossignol, M. E. Rice, and R. P. Machold, "Opposing regulation of dopaminergic activity and exploratory motor behavior by forebrain and brainstem cholinergic circuits," Nature Communications, vol. 3, article 1172, 2012.

[50] S. N. Young and S. Gauthier, "Effect of tryptophan administration on tryptophan, 5-hydroxyindoleacetic acid and indoleacetic acid in human lumbar and cisternal cerebrospinal fluid," Journal of Neurology Neurosurgery and Psychiatry, vol. 44, no. 4, pp. 323-328, 1981.

[51] N. Zárraga-Galindo, P. Vergara-Aragón, S. Rosales-Meléndez et al., "Effects of bee products on pentylenetetrazole-induced seizures in the rat," Proceedings of the Western Pharmacological Society, vol. 54, pp. 32-39, 2011.

[52] T. C. Frank-Cannon, L. T. Alto, F. E. McAlpine, and M. G. Tansey, "Does neuroinflammation fan the flame in neurodegenerative diseases?” Molecular Neurodegeneration, vol. 4, no. 1, article 47, 2009.

[53] M. J. Carson, J. C. Thrash, and B. Walter, "The cellular response in neuroinflammation: the role of leukocytes, microglia and astrocytes in neuronal death and survival," Clinical Neuroscience Research, vol. 6, no. 5, pp. 237-245, 2006.

[54] M. A. Akanmu, C. Echeverry, F. Rivera, and F. Dajas, "Antioxidant and neuroprotective effects of Nigerian honey," in Proceedings of the Nueroscience Meeting Planner, Washington, DC, USA, 2009.

[55] S. Schmitt-Schillig, S. Schaffer, C. C. Weber, G. P. Eckert, and W. E. Müller, "Flavonoids and the aging brain," Journal of Physiology and Pharmacology, vol. 56, no. 1, pp. 23-36, 2005.

[56] E. Esposito, D. Rotilio, V. di Matteo, C. di Giulio, M. Cacchio, and S. Algeri, "A review of specific dietary antioxidants and the effects on biochemical mechanisms related to neurodegenerative processes," Neurobiology of Aging, vol. 23, no. 5, pp. 719-735, 2002.

[57] F. C. Lau, B. Shukitt-Hale, and J. A. Joseph, "The beneficial effects of fruit polyphenols on brain aging," Neurobiology of Aging, vol. 26, pp. S128-S132, 2005.

[58] L. Shu-Qin, S. Fang, F. Lu-Mei, X. Qiang, and Z. Xiong, "Protective effect of apigenin on neurons against oxygenglucose deprivation/reperfusion induced injury," The FASEB Journal, vol. 604, 2010.

[59] J. Y. Han, S. Y. Ahn, C. S. Kim et al., "Protection of apigenin against kainate-induced excitotoxicity by anti-oxidative effects," Biological and Pharmaceutical Bulletin, vol. 35, no. 9, pp. 14401446, 2012.

[60] K. Rezai-Zadeh, J. Ehrhart, Y. Bai et al., "Apigenin and luteolin modulate microglial activation via inhibition of STAT1-induced CD40 expression," Journal of Neuroinflammation, vol. 5, article 41, 2008.

[61] C.-H. Jeong, H. R. Jeong, G. N. Choi, D.-O. Kim, U. Lee, and H. J. Heo, "Neuroprotective and anti-oxidant effects of caffeic acid isolated from Erigeron annuus leaf," Chinese Medicine, vol. 6, article 25, 2011.
[62] J.-Q. Yang, Q.-X. Zhou, B.-Z. Liu, and B.-C. He, "Protection of mouse brain from aluminum-induced damage by caffeic acid," CNS Neuroscience \& Therapeutics, vol. 14, no. 1, pp. 10-16, 2008.

[63] J. Anwar, R. M. Spanevello, G. Thomé et al., "Effects of caffeic acid on behavioral parameters and on the activity of acetylcholinesterase in different tissues from adult rats," Pharmacology Biochemistry and Behavior, vol. 103, no. 2, pp. 386-394, 2012.

[64] B. A. Sutherland, R. M. A. Rahman, and I. Appleton, "Mechanisms of action of green tea catechins, with a focus on ischemiainduced neurodegeneration," The Journal of Nutritional Biochemistry, vol. 17, no. 5, pp. 291-306, 2006.

[65] T. Kakuda, "Neuroprotective effects of the green tea components theanine and catechins," Biological and Pharmaceutical Bulletin, vol. 25, no. 12, pp. 1513-1518, 2002.

[66] S. A. Mandel, Y. Avramovich-Tirosh, L. Reznichenko et al., "Multifunctional activities of green tea catechins in neuroprotection: modulation of cell survival genes, iron-dependent oxidative stress and PKC signaling pathway," NeuroSignals, vol. 14, no. 1-2, pp. 46-60, 2005.

[67] K. Unno, F. Takabayashi, H. Yoshida et al., "Daily consumption of green tea catechin delays memory regression in aged mice," Biogerontology, vol. 8, no. 2, pp. 89-95, 2007.

[68] Q. Li, H. F. Zhao, Z. F. Zhang et al., "Long-term green tea catechin administration prevents spatial learning and memory impairment in senescence-accelerated mouse prone- 8 mice by decreasing $\mathrm{A} \beta 1-42$ oligomers and upregulating synaptic plasticity-related proteins in the hippocampus," Neuroscience, vol. 163, no. 3, pp. 741-749, 2009.

[69] J. Wang, L. Ho, Z. Zhao et al., "Moderate consumption of Cabernet Sauvignon attenuates $\mathrm{A} \beta$ neuropathology in a mouse model of Alzheimer's disease," The FASEB Journal, vol. 20, no. 13, pp. 2313-2320, 2006.

[70] Y. Li, W. Shi, Y. Li et al., "Neuroprotective effects of chlorogenic acid against apoptosis of PC12 cells induced by methylmercury," Environmental Toxicology and Pharmacology, vol. 26, no. 1, pp. 13-21, 2008.

[71] S.-H. Kwon, H.-K. Lee, J.-A. Kim et al., "Neuroprotective effects of chlorogenic acid on scopolamine-induced amnesia via anti-acetylcholinesterase and anti-oxidative activities in mice," European Journal of Pharmacology, vol. 649, no. 1-3, pp. 210-217, 2010.

[72] M. D. dos Santos, M. C. Almeida, N. P. Lopes, and G. E. P. de Souza, "Evaluation of the anti-inflammatory, analgesic and antipyretic activities of the natural polyphenol chlorogenic acid," Biological and Pharmaceutical Bulletin, vol. 29, no. 11, pp. 2236-2240, 2006.

[73] C. Wolfman, H. Viola, A. Paladini, F. Dajas, and J. H. Medina, "Possible anxiolytic effects of chrysin, a central benzodiazepine receptor ligand isolated from Passiflora coerulea," Pharmacology Biochemistry and Behavior, vol. 47, no. 1, pp. 1-4, 1994.

[74] X.-L. He, Y.-H. Wang, M.-G. Bi, and G.-H. Du, "Chrysin improves cognitive deficits and brain damage induced by chronic cerebral hypoperfusion in rats," European Journal of Pharmacology, vol. 680, no. 1-3, pp. 41-48, 2012.

[75] L. R. Ferguson, S.-T. Zhu, and P. J. Harris, "Antioxidant and antigenotoxic effects of plant cell wall hydroxycinnamic acids in cultured HT-29 cells," Molecular Nutrition \& Food Research, vol. 49, no. 6, pp. 585-593, 2005.

[76] M. H. Abdel-Wahab, M. A. El-Mahdy, M. F. Abd-Ellah, G. K. Helal, F. Khalifa, and F. M. A. Hamada, "Influence of pcoumaric acid on doxorubicin-induced oxidative stress in rat's 
heart," Pharmacological Research, vol. 48, no. 5, pp. 461-465, 2003.

[77] D. Vauzour, G. Corona, and J. P. E. Spencer, "Caffeic acid, tyrosol and p-coumaric acid are potent inhibitors of 5-S-cysteinyldopamine induced neurotoxicity," Archives of Biochemistry and Biophysics, vol. 501, no. 1, pp. 106-111, 2010.

[78] N. P. Seeram, L. S. Adams, S. M. Henning et al., "In vitro antiproliferative, apoptotic and antioxidant activities of punicalagin, ellagic acid and a total pomegranate tannin extract are enhanced in combination with other polyphenols as found in pomegranate juice," The Journal of Nutritional Biochemistry, vol. 16, no. 6, pp. 360-367, 2005.

[79] E. Uzar, H. Alp, M. U. Cevik et al., "Ellagic acid attenuates oxidative stress on brain and sciatic nerve and improves histopathology of brain in streptozotocin-induced diabetic rats," Neurological Sciences, vol. 33, no. 3, pp. 567-574, 2012.

[80] C.-Y. Cheng, S.-Y. Su, N.-Y. Tang, T.-Y. Ho, S.-Y. Chiang, and C.L. Hsieh, "Ferulic acid provides neuroprotection against oxidative stress-related apoptosis after cerebral ischemia/reperfusion injury by inhibiting ICAM-1 mRNA expression in rats," Brain Research, vol. 1209, pp. 136-150, 2008.

[81] C.-Y. Cheng, S.-Y. Su, N.-Y. Tang, T.-Y. Ho, W.-Y. Lo, and C.L. Hsieh, "Ferulic acid inhibits nitric oxide-induced apoptosis by enhancing GABA B1 receptor expression in transient focal cerebral ischemia in rats," Acta Pharmacologica Sinica, vol. 31, no. 8, pp. 889-899, 2010.

[82] Y. Luo, H.-P. Zhao, J. Zhang et al., "Effect of ferulic acid on learning and memory impairments of vascular dementia rats and its mechanism of action," Acta Pharmaceutica Sinica, vol. 47, no. 2, pp. 256-260, 2012.

[83] M. J. Kim, S. J. Choi, S.-T. Lim et al., "Ferulic acid supplementation prevents trimethyltin-induced cognitive deficits in mice," Bioscience, Biotechnology and Biochemistry, vol. 71, no. 4, pp. 1063-1068, 2007.

[84] J. Y. Ban, H. T. T. Nguyen, H.-J. Lee et al., "Neuroprotective properties of gallic acid from Sanguisorbae radix on amyloid $\beta$ protein (25-35)-induced toxicity in cultured rat cortical neurons," Biological and Pharmaceutical Bulletin, vol. 31, no. 1, pp. 149-153, 2008.

[85] D. Dhingra, R. Chhillar, and A. Gupta, "Antianxiety-like activity of gallic acid in unstressed and stressed mice: possible involvement of nitriergic system," Neurochemical Research, vol. 37, no. 3, pp. 487-494, 2012.

[86] A. S. Al Mansouri, D. E. Lorke, S. M. Nurulain et al., "Methylene blue inhibits the function of a7-nicotinic acetylcholine receptors," CNS and Neurological Disorders: Drug Targets, vol. 11, no. 6, pp. 791-800, 2012.

[87] M. T. Mansouri, Y. Farbood, M. J. Sameri, A. Sarkaki, and B. Naghizadeh, "Neuroprotective effects of oral gallic acid against oxidative stress induced by 6-hydroxydopamine in rats," Food Chemistry, vol. 138, no. 2-3, pp. 1028-1033, 2013.

[88] S. Li and X.-P. Pu, "Neuroprotective effect of kaempferol against a 1-methyl-4-phenyl-1,2,3,6- tetrahydropyridineinduced mouse model of Parkinson's disease," Biological and Pharmaceutical Bulletin, vol. 34, no. 8, pp. 1291-1296, 2011.

[89] G. Filomeni, I. Graziani, D. de Zio et al., "Neuroprotection of kaempferol by autophagy in models of rotenone-mediated acute toxicity: possible implications for Parkinson's disease," Neurobiology of Aging, vol. 33, no. 4, pp. 767-785, 2012.

[90] P. Soo-Hyun, S. Yun-Beom, H. Pyung-Lim, L. Jin-Koo, and S. Hong-Won, "Antidepressant-like effect of Kaempferol and
Quercitirin, isolated from Opuntia ficus-indica var. saboten," Experimental Neurobiology, vol. 19, no. 1, pp. 30-38, 2010.

[91] Y. Lin, R. Shi, X. Wang, and H.-M. Shen, "Luteolin, a flavonoid with potential for cancer prevention and therapy," Current Cancer Drug Targets, vol. 8, no. 7, pp. 634-646, 2008.

[92] S. Jang, R. N. Dilger, and R. W. Johnson, "Luteolin inhibits microglia and alters hippocampal-dependent spatial working memory in aged mice," Journal of Nutrition, vol. 140, no. 10, pp. 1892-1898, 2010.

[93] F.-S. Tsai, W.-H. Peng, W.-H. Wang et al., "Effects of luteolin on learning acquisition in rats: involvement of the central cholinergic system," Life Sciences, vol. 80, no. 18, pp. 1692-1698, 2007.

[94] F.-S. Tsai, H.-Y. Cheng, M.-T. Hsieh, C.-R. Wu, Y.-C. Lin, and W.-H. Peng, "The ameliorating effects of luteolin on beta-amyloid-induced impairment of water maze performance and passive avoidance in rats," American Journal of Chinese Medicine, vol. 38, no. 2, pp. 279-291, 2010.

[95] B. Xu, X.-X. Li, G.-R. He et al., "Luteolin promotes longterm potentiation and improves cognitive functions in chronic cerebral hypoperfused rats," European Journal of Pharmacology, vol. 627, no. 1-3, pp. 99-105, 2010.

[96] Y. Oyama, P. A. Fuchs, N. Katayama, and K. Noda, "Myricetin and quercetin, the flavonoid constituents of Ginkgo biloba extract, greatly reduce oxidative metabolism in both resting and $\mathrm{Ca}^{2+}$-loaded brain neurons," Brain Research, vol. 635, no. 1-2, pp. 125-129, 1994.

[97] M. F. Molina-Jiménez, M. I. Sánchez-Reus, D. Andres, M. Cascales, and J. Benedi, "Neuroprotective effect of fraxetin and myricetin against rotenone-induced apoptosis in neuroblastoma cells," Brain Research, vol. 1009, no. 1-2, pp. 9-16, 2004.

[98] Y. Lei, J. Chen, W. Zhang et al., "In vivo investigation on the potential of galangin, kaempferol and myricetin for protection of D-galactose-induced cognitive impairment," Food Chemistry, vol. 135, no. 4, pp. 2702-2707, 2012.

[99] N. Braidy, R. Grant, S. Adams, and G. J. Guillemin, "Neuroprotective effects of naturally occurring polyphenols on quinolinic acid-induced excitotoxicity in human neurons," FEBS Journal, vol. 277, no. 2, pp. 368-382, 2010.

[100] H. J. Heo, D.-O. Kim, S. C. Shin, M. J. Kim, B. G. Kim, and D.-H. Shin, "Effect of antioxidant flavanone, naringenin, from Citrus junoson neuroprotection," Journal of Agricultural and Food Chemistry, vol. 52, no. 6, pp. 1520-1525, 2004.

[101] T. Baluchnejadmojarad and M. Roghani, "Effect of naringenin on intracerebroventricular streptozotocin-induced cognitive deficits in rat: a behavioral analysis," Pharmacology, vol. 78, no. 4, pp. 193-197, 2006.

[102] M. B. Khan, M. M. Khan, A. Khan et al., "Naringenin ameliorates Alzheimer's disease (AD)-type neurodegeneration with cognitive impairment (AD-TNDCI) caused by the intracerebroventricular-streptozotocin in rat model," Neurochemistry International, vol. 61, no. 7, pp. 1081-1093, 2012.

[103] T.-J. Chen, J.-Y. Jeng, C.-W. Lin, C.-Y. Wu, and Y.-C. Chen, "Quercetin inhibition of ROS-dependent and -independent apoptosis in rat glioma C6 cells," Toxicology, vol. 223, no. 1-2, pp. 113-126, 2006.

[104] L. D. Mercer, B. L. Kelly, M. K. Horne, and P. M. Beart, “Dietary polyphenols protect dopamine neurons from oxidative insults and apoptosis: investigations in primary rat mesencephalic cultures," Biochemical Pharmacology, vol. 69, no. 2, pp. 339-345, 2005. 
[105] P. Hu, M. Wang, W.-H. Chen et al., "Quercetin relieves chronic lead exposure-induced impairment of synaptic plasticity in rat dentate gyrus in vivo," Naunyn-Schmiedeberg's Archives of Pharmacology, vol. 378, no. 1, pp. 43-51, 2008.

[106] A. Kumar, N. Sehgal, P. Kumar, S. S. V. Padi, and P. S. Naidu, "Protective effect of quercetin against ICV colchicineinduced cognitive dysfunctions and oxidative damage in rats," Phytotherapy Research, vol. 22, no. 12, pp. 1563-1569, 2008.

[107] V. Sharma, M. Mishra, S. Ghosh et al., "Modulation of interleukin- $1 \beta$ mediated inflammatory response in human astrocytes by flavonoids: implications in neuroprotection," Brain Research Bulletin, vol. 73, no. 1-3, pp. 55-63, 2007.

[108] F. Dajas, A. Rivera-Megret, F. Blasina et al., "Neuroprotection by flavonoids," Brazilian Journal of Medical and Biological Research, vol. 36, no. 12, pp. 1613-1620, 2003.

[109] F. Pu, K. Mishima, K. Irie et al., "Neuroprotective effects of quercetin and rutin on spatial memory impairment in an 8arm radial maze task and neuronal death induced by repeated cerebral ischemia in rats," Journal of Pharmacological Sciences, vol. 104, no. 4, pp. 329-334, 2007.

[110] E. Schültke, E. Kendall, H. Kamencic, Z. Ghong, R. W. Griebel, and B. H. J. Juurlink, "Quercetin promotes functional recovery following acute spinal cord injury," Journal of Neurotrauma, vol. 20, no. 6, pp. 583-591, 2003.

[111] M. Repici, J. Mariani, and T. Borsello, "Neuronal death and neuroprotection: a review," Methods in Molecular Biology, vol. 399, pp. 1-14, 2007.

[112] R. Tarawneh and J. E. Galvin, "Potential future neuroprotective therapies for neurodegenerative disorders and stroke," Clinics in Geriatric Medicine, vol. 26, no. 1, pp. 125-147, 2010.

[113] H. Gavin, B. Philip, and N. Philip, "Appoptosis, necrosis and much more-is oxidative stress gattings in your nerves?" Australian Biochemists, vol. 43, no. 1, pp. 16-20.

[114] F. J. E. Vajda, "Neuroprotection and neurodegenerative disease," Journal of Clinical Neuroscience, vol. 9, no. 1, pp. 4-8, 2002.

[115] G. P. Kumar and K. Farhath, "Neuroprotective potential of phytochemicals," Pharmacognosy Reviews, vol. 6, no. 12, pp. 8190, 2012.

[116] N. A. Kelsey, H. M. Wilkins, and D. A. Linseman, "Nutraceutical antioxidants as novel neuroprotective agents," Molecules, vol. 15, no. 11, pp. 7792-7814, 2010.

[117] M. P. Mattson, T. G. Son, and S. Camandola, "Viewpoint: mechanisms of action and therapeutic potential of neurohormetic phytochemicals," Dose Response, vol. 5, no. 3, pp. 174-186, 2007.

[118] R. Kannappan, S. C. Gupta, J. H. Kim, S. Reuter, and B. B. Aggarwal, "Neuroprotection by spice-derived nutraceuticals: you are what you eat!," Molecular Neurobiology, vol. 44, no. 3, pp. 142-159, 2011.

[119] S. J. Martin, P. D. Grimwood, and R. G. M. Morris, "Synaptic plasticity and memory: an evaluation of the hypothesis," Annual Review of Neuroscience, vol. 23, pp. 649-711, 2000.

[120] A. Matynia, S. A. Kushner, and A. J. Silva, "Genetic approaches to molecular and cellular cognition: a focus on LTP and learning and memory," Annual Review of Genetics, vol. 36, pp. 687-720, 2002.

[121] E. Thiels, B. I. Kanterewicz, E. D. Norman, J. M. Trzaskos, and E. Klann, "Long-term depression in the adult hippocampus in vivo involves activation of extracellular signal-regulated kinase and phosphorylation of Elk-1," Journal of Neuroscience, vol. 22, no. 6, pp. 2054-2062, 2002.
[122] J. D. Sweatt, "Toward a molecular explanation for long-term potentiation," Learning and Memory, vol. 6, no. 5, pp. 399-416, 1999.

[123] R. A. Nicoll and R. C. Malenka, "Contrasting properties of two forms of long-term potentiation in the hippocampus," Nature, vol. 377, no. 6545, pp. 115-118, 1995.

[124] G. Voglis and N. Tavernarakis, "The role of synaptic ion channels in synaptic plasticity," EMBO Reports, vol. 7, no. 11, pp. 1104-1110, 2006.

[125] S. Larry, B. Darwin, E. B. Floyd et al., Fundamental Neuroscience, Elsevier Science, New York, NY, USA, 2003.

[126] T. V. P. Bliss and G. L. Collingridge, "A synaptic model of memory: long-term potentiation in the hippocampus," Nature, vol. 361, no. 6407, pp. 31-39, 1993.

[127] P. V. Nguyen and E. R. Kandel, "A macromolecular synthesisdependent late phase of long-term potentiation requiring cAMP in the medial perforant pathway of rat hippocampal slices," Journal of Neuroscience, vol. 16, no. 10, pp. 3189-3198, 1996.

[128] M. W. Swank and J. D. Sweatt, "Increased histone acetyltransferase and lysine acetyltransferase activity and biphasic activation of the ERK/RSK cascade in insular cortex during novel taste learning," Journal of Neuroscience, vol. 21, no. 10, pp. 3383-3391, 2001.

[129] A. Lanahan and P. Worley, "Immediate-early genes and synaptic function," Neurobiology of Learning and Memory, vol. 70, no. 12, pp. 37-43, 1998.

[130] "Guidance for Industry: A Food Labeling Guide (14. Appendix F: Calculate the Percent Daily Value for the Appropriate Nutrients)," 2013, http://www.fda.gov/food/guidanceregulation/guidancedocumentsregulatoryinformation/labelingnutrition/ucm064928.htm.

[131] ECFR, "Electronic code of federal regulations," http://ecfr .gpoaccess.gov/. 


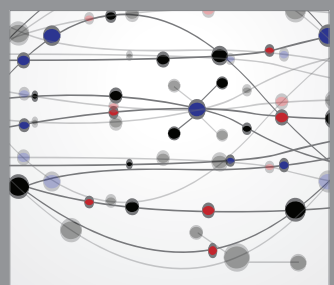

The Scientific World Journal
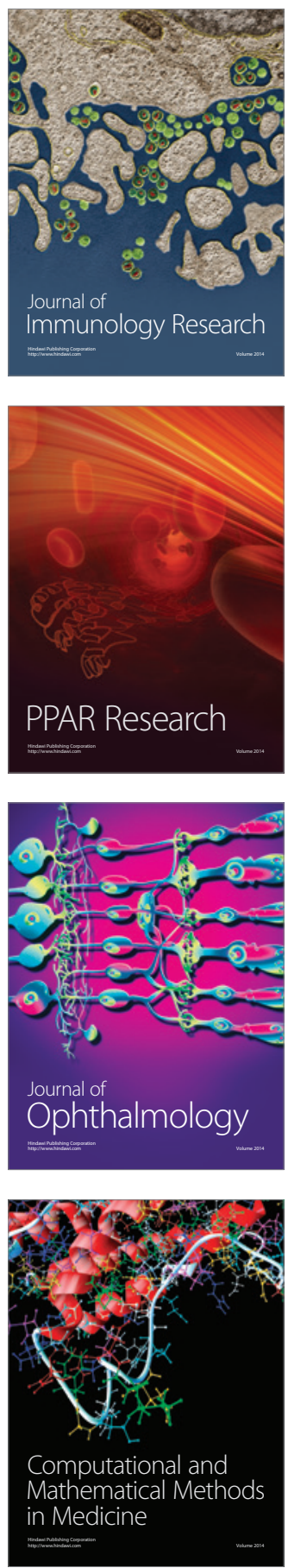

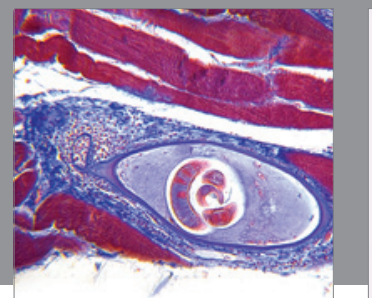

Gastroenterology

Research and Practice
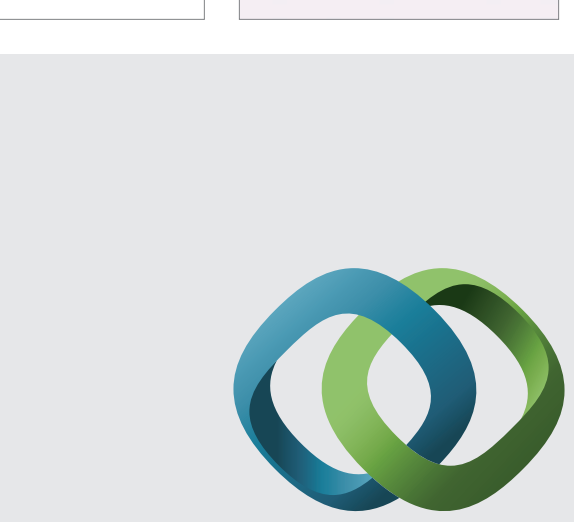

\section{Hindawi}

Submit your manuscripts at

http://www.hindawi.com
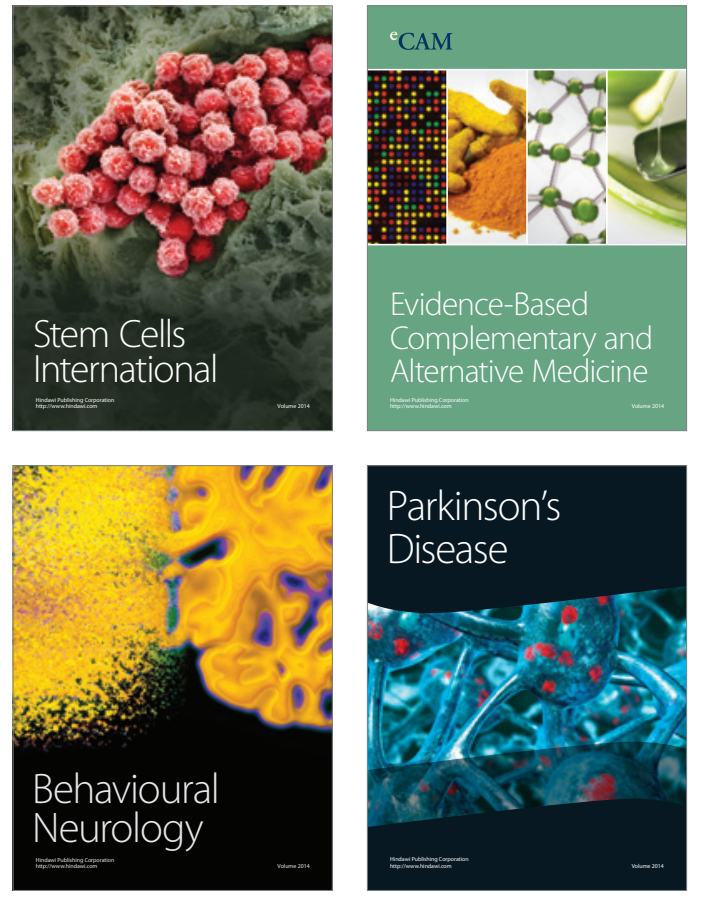
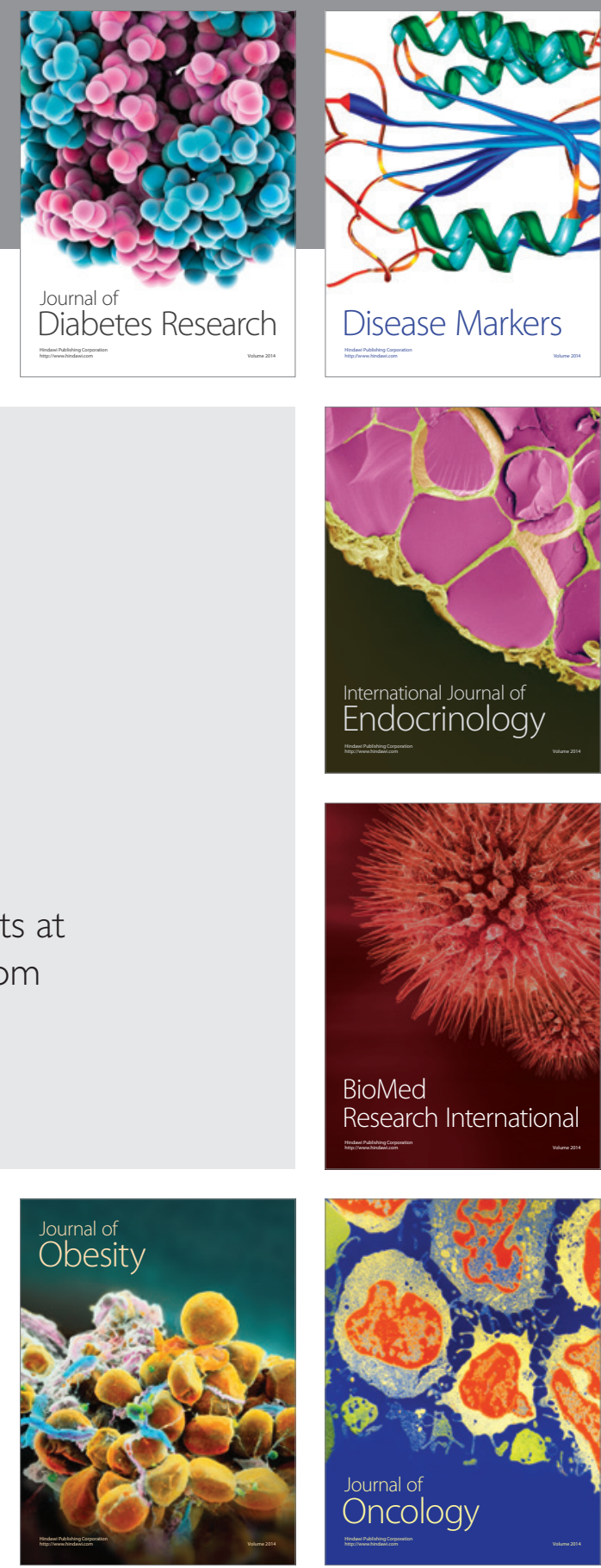

Disease Markers
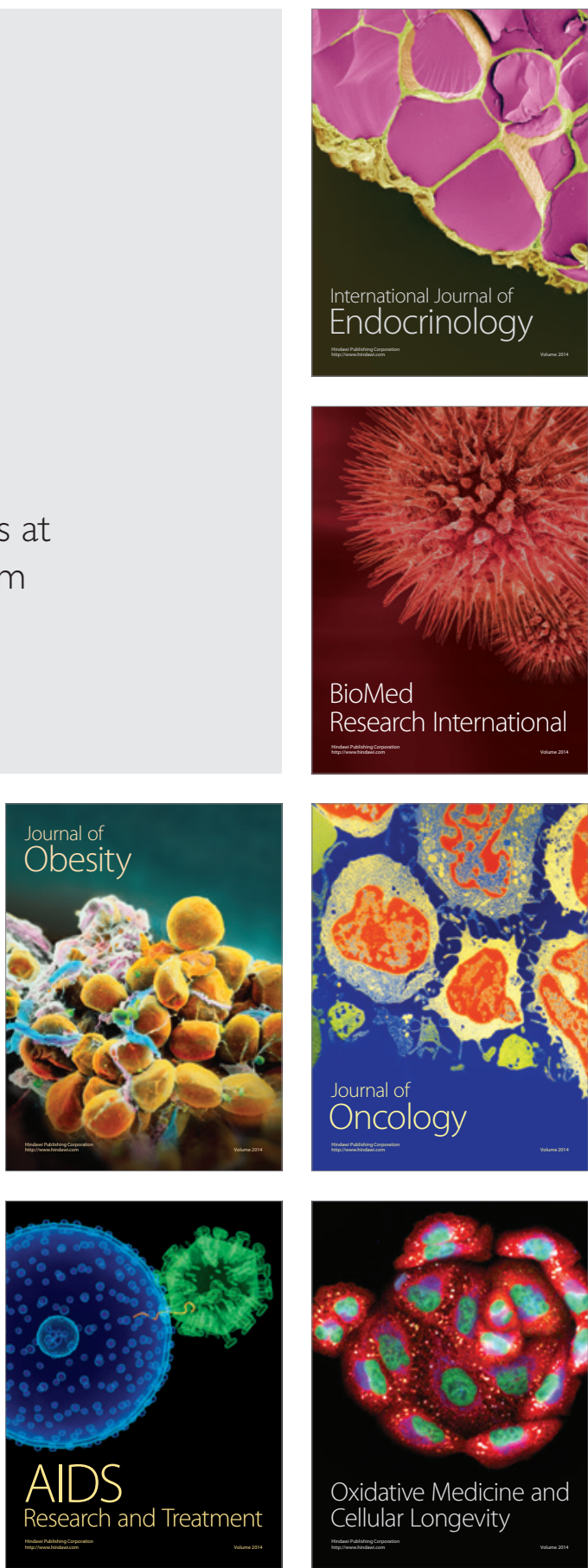